\title{
COMPLICATIONS IN ORTHOGNATHIC SURGERY: A RETROSPECTIVE STUDY
}

\author{
Moustafa M Taha*, Amr A Ghanem **, Mohamed A Amin ${ }^{* * *}$ and Karim M Abdelmohsen*
}

\begin{abstract}
Orthognathic surgery is safe and reliable surgery, but in rare cases there may be some complications that can be disastrous and even sometimes fatal. In this study, we aim to analyze the different types of complications in orthodontic surgeries. This study is a retrospective investigation of the records of 12 patients who underwent orthognathic surgery between 2015 and 2016 in the Department of Oral and Maxillofacial Surgery at Ain Shams University, Cairo, Egypt. The types of complications were documented, and separate surgical factors were recorded and evaluated. A number of complications have been identified, such as poor bite of teeth after surgery, morbidity or nerve pain, failure of plates and screws and relapse. We found that more complications were present in the time consuming surgeries. In summary, postoperative malocclusion, bad split and infection are the most common complications in orthodontic surgeries.
\end{abstract}

KEY WORDS: Complications, orthognathic surgery, malocclusion

\section{INTRODUCTION}

Orthognathic procedures are combined surgical and orthodontic maneuvers performed to restore facial and cranial balance ${ }^{1}$. A wide array of complications had always been associated with these surgeries. This may be attributed to the accurate planning required and the complexity of the performed surgeries ${ }^{2}$. These complications can be divided into 3 categories; complications caused by errors in the preoperative planning, intraoperative complications and postoperative ones ${ }^{3}$. There are two main protocols for pre-operative planning; model surgery (conventional technique) and virtual planning. Assuming the advantages of model surgery being more feasible, cheaper and widely available, the present manuscript demonstrates the clinical outcome of conventional techniques used in pre-planning. Intraoperative complications are not uncommon. They may include neurosensory compromise, hemorrhage, unfavorable fractures, perforation of the endotracheal tube and oroantral communication $^{4}$. Last but not least postoperative

* Lecturer Oral and Maxillofacial Surgery Department Ainshams University.

** Assistant Professor Oral and Maxillofacial Surgery Department Ainshams University.

*** Associate Professor Plastic and Reconstructive Surgery Department Ainshams University. 
complications may be the most frustrating ones as mostly they may need resurgical intervention. This includes looseness of the fixation hardware, infection, vascular compromise, gingival necrosis, malocclusion, as well as temporomandibular joint dysfunction ${ }^{5 ; 6 .}$.

Literature has been divided postoperative complications of orthognathic surgery into immediate postoperative complications and complications that develop some time after surgery. Late post-operative complications can occur up to two years postoperatively. This may be attributed to progressive volumetric changes in the mandibular condyles in cases where a sagittal split osteotomy is part of the operative procedure ${ }^{7}$

Discussing the possible complications associated with orthognathic procedures had raised the concern about the need for retrospective analysis of our operated cases. This is performed with the aim of denoting the quality of what is presented to our patients and the possible ways to improve this outcome.

\section{PATIENTS AND METHODS}

A retrospective review of the orthognathic cases operated in Ain shams university throughout 20152016 was performed. Data was collected from the recording systems in both the departments of orthodontic and oral and maxillofacial surgery. Cases receiving either single or bimaxillary surgeries were included. Electronic form was used to collect several data from the records available for each patient which included:

1. Type of the Dento facial deformity.

2. The treatment plan proposed.

3. Operation time.

4. Volume of Blood loss.

5. Post-operative care and time of hospital stay.
6. Surgical technique employed.

7. Type of fixation used

8. The need for reoperation

9. Postoperative occlusion and relapse

10. Follow up period

\section{Data Management and Analysis:}

The collected data was revised, coded, tabulated and introduced to a PC Statistical package for Social Science (SPSS 15.0 for windows; SPSS Inc, Chicago, IL, 2001). Data was presented and suitable analysis was done according to the type of data obtained for each parameter.

\section{Descriptive statistics:}

$\circ$ Frequency and percentage of non-numerical data.

\section{Analytical statistics:}

1. Chi-Square test was used to examine the relationship between two qualitative variables.

2. Fisher's exact Chi-Square test is computed when a table that does not result from missing rows or columns in a larger table has a cell with an expected frequency of less than 5 .

P-value: level of significance

$-\mathrm{P}>0.05$ : Not significant (NS).

$-\mathrm{P} \leq$ 0.05: Significant $(\mathrm{S})$.

$-\mathrm{P} \leq 0.01$ : Highly significant (HS).

\section{RESULTS}

A total of 12 patients ( 7 females \&5males) where operated in the time period between 2015-2016. The age of the patients ranged between 20-30 years of age. Two patients had previous surgeries to address a cleft lip/ palate anomaly (Table 1 ). 
TABLE (1): Frequency of a deformity for the studied cases

\begin{tabular}{|l|c|c|}
\hline \multicolumn{1}{|c|}{ Deformity } & $\begin{array}{c}\text { Frequency } \\
(\mathrm{n}=12)\end{array}$ & Percent\% \\
\hline$V M E+M D$ & $\mathbf{2}$ & $\mathbf{1 6 . 7 \%}$ \\
\hline$M x D+M E$ & $\mathbf{3}$ & $\mathbf{2 5 . 0 \%}$ \\
\hline$M D$ & $\mathbf{1}$ & $\mathbf{8 . 3 \%}$ \\
\hline$M x D+M E(C P)$ & $\mathbf{2}$ & $\mathbf{1 6 . 7 \%}$ \\
\hline$M E$ & $\mathbf{2}$ & $\mathbf{1 6 . 7 \%}$ \\
\hline$P M$ & $\mathbf{1}$ & $\mathbf{8 . 3 \%}$ \\
\hline$V M E$ & $\mathbf{1}$ & $\mathbf{8 . 3 \%}$ \\
\hline
\end{tabular}

Vertical maxillary excess $=V M E$, Mandibular deficiency $=$ MD, Mandibular Excess $=$ ME, Maxillary deficiency $=$ $M x D, C P=$ cleft palate, Postoperative malocclusion $=P M$

The surgical plan was analyzed in terms of frequency as well as magnitude of surgical movement for descriptive purposes. (table2)

The time of the surgical procedures was subjected also to analytical study (Table 3). A Fisher's Exact Chi-square Test was utilized to study the correlation between the surgical procedures and the time spent in the operating theatre. There was no statistically significant difference; between the surgical type either single or double jaw and the time of surgery (Table 4).
TABLE (2): Frequency of surgical plan for the studied cases

\begin{tabular}{|l|c|c|}
\hline \multicolumn{1}{|c|}{ Plan } & $\begin{array}{c}\text { Frequency } \\
(\mathbf{n = 1 2})\end{array}$ & $\begin{array}{c}\text { Percent } \\
\%\end{array}$ \\
\hline $\begin{array}{l}\text { Max. impaction, mand. } \\
\text { advancement, genioplasty }\end{array}$ & 1 & $8.3 \%$ \\
\hline $\begin{array}{l}\text { BSSO Rt. side 8mm, Lt side } \\
\text { 5mm(setback) }\end{array}$ & 2 & $16.7 \%$ \\
\hline Max. adv+ BSSO set back & 3 & $25 \%$ \\
\hline Set back 5mm & 2 & $16.7 \%$ \\
\hline $\begin{array}{l}\text { Max. adv 4mm+ post max. impaction } \\
\text { 3mm+ mand. set back 4mm }\end{array}$ & 1 & $8.3 \%$ \\
\hline Bsso and auto rotation & 1 & $8.3 \%$ \\
\hline $\begin{array}{l}\text { Max. impaction 8mm, BSSO adv. } \\
\text { 12mm }\end{array}$ & 1 & $8.3 \%$ \\
\hline Max. impaction 8 mm & 1 & $8.3 \%$ \\
\hline
\end{tabular}

TABLE (3): Frequency of time of surgery for the studied cases

\begin{tabular}{lcc}
\hline $\begin{array}{c}\text { Surgery time } \\
\text { (hours) }\end{array}$ & $\begin{array}{c}\text { Frequency } \\
(\mathrm{n}=12)\end{array}$ & Percent $\%$ \\
Three & $\mathbf{3}$ & $\mathbf{2 5 \%}$ \\
Four & $\mathbf{3}$ & $\mathbf{2 5 \%}$ \\
Five & $\mathbf{3}$ & $\mathbf{2 5 \%}$ \\
Six & $\mathbf{2}$ & $\mathbf{1 6 . 7 \%}$ \\
Seven & $\mathbf{1}$ & $\mathbf{8 . 3 \%}$ \\
\hline
\end{tabular}

TABLE (4): Comparison between time of surgery and surgery type

\begin{tabular}{|c|c|c|c|c|c|c|c|}
\hline $\begin{array}{l}\text { Time } \\
\text { (hours) }\end{array}$ & $\begin{array}{l}\text { Max. } \\
(n=1)\end{array}$ & $\begin{array}{l}\text { Mand. } \\
(\mathrm{n}=5)\end{array}$ & $\begin{array}{l}\text { Double jaw } \\
\qquad(\mathrm{n}=6)\end{array}$ & $\begin{array}{c}\text { Total } \\
(n=12)\end{array}$ & $X^{2}$ & P Value & Sig. \\
\hline Three & 0 & $3(60.0 \%)$ & 0 & $3(25 \%)$ & \multirow{5}{*}{9.96} & \multirow{5}{*}{0.304} & \multirow{5}{*}{ NS } \\
\hline Four & 0 & $1(20.0 \%)$ & $2(33.3 \%)$ & $3(25 \%)$ & & & \\
\hline Five & $1(100 \%)$ & 0 & $2(33.3 \%)$ & $3(25 \%)$ & & & \\
\hline Six & 0 & $1(20.0 \%)$ & $1(16.7 \%)$ & $2(16.7 \%)$ & & & \\
\hline Seven & 0 & 0 & $1(16.7 \%)$ & $1(8.3 \%)$ & & & \\
\hline
\end{tabular}




\section{Fisher's Exact Chi-square Test}

The frequency of blood loss management of these surgical cases was also assessed.

No blood transfusion was done in any of the performed cases in our study sample. However, volume enhancers were only utilized in two cases (Table 5).

TABLE (5): Frequency of blood loss for the studied cases

\begin{tabular}{|l|c|c|}
\hline \multicolumn{1}{|c|}{ Blood loss } & $\begin{array}{c}\text { Frequency } \\
(\mathrm{n}=12)\end{array}$ & $\begin{array}{c}\text { Percent } \\
\%\end{array}$ \\
\hline No replacement & 10 & $83.3 \%$ \\
\hline Volume enhancers required & 2 & $16.7 \%$ \\
\hline
\end{tabular}

Two patients were admitted in the intermediate intensive care unit in our department following bimaxillary surgery. The causes were air way edema in one patient and postoperative bradycardia during recovery was for the other one. Both cases were dismissed to the ward in six hours (table 6).

TABLE (6): Frequency of post-operative care for the studied cases

\begin{tabular}{|l|c|c|}
\hline \multicolumn{1}{|c|}{ Post-operative care } & $\begin{array}{c}\text { Frequency } \\
(\mathrm{n}=12)\end{array}$ & Percent\% \\
\hline $\begin{array}{l}\text { intermediate care due to } \\
\text { bradycardia }\end{array}$ & 1 & $8.3 \%$ \\
\hline Day case & 10 & $83.3 \%$ \\
\hline $\begin{array}{l}\text { intermediate care for airway } \\
\text { compromise }\end{array}$ & 1 & $8.3 \%$ \\
\hline
\end{tabular}

All patients were followed up during the postoperative period until de bonding of the orthodontic brackets. The occlusion was deemed acceptable when the orthodontic team reached the desired class1 canine and molar relationship. Records of relapse or occlusal changes were subjected to analysis. (table 7)

TABLE (7): Frequency of post-operative occlusion for the studied cases

\begin{tabular}{|c|c|c|}
\hline Post-operative occlusion & $\begin{array}{c}\text { Frequency } \\
(\mathrm{n}=12)\end{array}$ & Percent $\%$ \\
\hline Acceptable & 9 & $75.0 \%$ \\
\hline Max. midline deviation & 2 & $16.7 \%$ \\
\hline open bite $2 \mathrm{~mm}$ & 1 & $8.3 \%$ \\
\hline
\end{tabular}

The post-operative complications as reported by the referring orthodontist and the surgeon were subjected to statistical assessment (table 8).

TABLE (8): Frequency of post-operative complications for the studied cases

\begin{tabular}{|c|c|c|}
\hline $\begin{array}{c}\text { Post-operative } \\
\text { complications }\end{array}$ & $\begin{array}{c}\text { Frequency } \\
(\mathrm{n}=12)\end{array}$ & Percent $\%$ \\
\hline None & 7 & $58.3 \%$ \\
\hline Alar flare & 1 & $8.3 \%$ \\
\hline Screw failure & 1 & $8.3 \%$ \\
\hline $\begin{array}{c}\text { Painless mobile maxilla } \\
\text { relapse }\end{array}$ & 1 & $8.3 \%$ \\
\hline Deficient chin & 1 & $8.3 \%$ \\
\hline Neruropyrexia on lt. side & 1 & $8.3 \%$ \\
\hline
\end{tabular}

The type of fixation utilized with mandibular osteotomies was studied as well. In addition, correlation between the type of fixation and postoperative surgical progress was studied using Fisher's Exact Chi-square Test. There was no statistically significant difference; between the fixation type and progress (table 9). 
TABLE (9): Comparison between type of fixation and progress

\begin{tabular}{|c|c|c|c|c|c|c|c|}
\hline Progress & $\begin{array}{l}\text { Screw } 2.0 \\
(n=3 / \text { side })\end{array}$ & $\begin{array}{l}\text { Screw } 2.3 \\
(n=3 / \text { side })\end{array}$ & $\begin{array}{l}\text { Plate } 2.0 \\
(\mathrm{n}=1 / \text { side })\end{array}$ & $\begin{array}{l}\text { Total } \\
(\mathrm{n}=11)\end{array}$ & $X^{2}$ & P value & Sig. \\
\hline normal & $1(33.3 \%)$ & $3(75 \%)$ & $2(50 \%)$ & $6(54.5 \%)$ & \multirow{6}{*}{9.97} & \multirow{6}{*}{0.766} & \multirow{6}{*}{ NS } \\
\hline re-operated & $1(33.3 \%)$ & 0 & 0 & $1(9.1 \%)$ & & & \\
\hline lost to follow up & $1(33.3 \%)$ & 0 & 0 & $1(9.1 \%)$ & & & \\
\hline Antroposerior. relapse & 0 & 0 & $1(25 \%)$ & $1(9.1 \%)$ & & & \\
\hline Vertical relapse & 0 & 0 & $1(25 \%)$ & $1(9.1 \%)$ & & & \\
\hline $\begin{array}{l}\text { referred for pain } \\
\text { therapy }\end{array}$ & 0 & $1(25 \%)$ & 0 & $1(9.1 \%)$ & & & \\
\hline
\end{tabular}

\section{DISCUSSION}

Orthognathic surgery consists of bony osteotomies performed in the masticatory system with the aim of correction of jaw discrepancies to establish facial and cranial harmony as well as provide correct dental positioning ${ }^{8}$. Therefore, orthognathic surgery is not merely a surgical procedure; it is described as a procedure combining orthodontia and oral maxillofacial surgery, which attempts to correct dentoskeletal irregularities ${ }^{9 ; 10}$.

Complications are inherent to any surgical procedure; therefore, professional knowledge is required to avoid most of complications. Hence, the aim of this manuscript was to introduce a comprehensive review of possible complications of orthognathic surgery based on our department's experience.

Orthognathic surgery is often associated with some degree of neurosensory disturbance.

It is important to educate patients before the procedure so that they are prepared for this in the post-operative course ${ }^{11}$. In the present study only one case showed temporary parathesia which resolved after two months.

In general, orthognathic surgery is not associated with significant blood loss. Review of the literature showed that, based on a number of reports, that serious bleeding intraoperatively and postoperatively is quite rare. The blood vessels mostly responsible for it include the descending palatine arteries, pterygoid venous plexus, masseteric artery, retro-mandibular vein, and the facial artery. Understanding vascular head and neck anatomy, common sources of hemorrhage, delicate tissue manipulation and proper case preparation can reduce risk of hemorrhage ${ }^{12 ; 13}$. In the current study only two cases required plasma expander substitution when blood loss was greater than $300 \mathrm{cc}$.

Unfavorable split or bad split is one of the most troublesome intraoperative complications, which could be problematic especially if mandible first technique is adopted in bimaxillary procedures. The most vital aspect of the osteotomy is to confirm proper inferior border separation during the sagittal osteotomy, monitor for equal separation of the two sides along the entire extent of the inferior border. The fractured segment can be secured as a free graft using plates/screws ${ }^{14: 15}$. In the present case series bad split did not happen in any of our patients.

Nasal abnormalities could be seen after maxillary surgery especially maxillary impaction and maxillary advancement. These abnormalities comprise nasal septal deviation, alar base widening, rotation of the tip of the nose and dorsal deformities ${ }^{16}$. Alar base cinch suture, nasal septum $r$ and inferior turbinate reduction are mandatory for prevention of those complications. All these defects could be corrected 
post-operatively however, proper surgical technique will prevent such complications ${ }^{17} ;{ }^{18}$. Minimal increase in the nasal base is very common due to soft tissue reflection during flap elevation, only one case in the present series showed slight nasal flare which decreased significantly in 3-months.

Malocclusion that could occurs either immediate post-operatively or delayed during follow-up is a common complication. Open bite (anterior or posterior) is the worst to happen ${ }^{19 ; 20}$. Open bite that happen Immediate after release of IMF occurs due to inadequate removal of posterior interferences and /or displacement of the condyles out of fossa during fixation ${ }^{21}$.

Late development of open bite could be attributed to loss of transverse expansion, orthodontic relapse, condylar resorption, and continued maxillomandibular growth. Literature revealed that subtle immediate postoperative occlusal discrepancies may be corrected with guidance elastics and enhanced neuromuscular reprogramming. However, significant open bite noticed immediately after release could necessities re-operation ${ }^{22}$. Additionally, late occlusal discrepancies should be corrected according to the underlying etiology. In our experience one case only exhibited persistent minimal open bite of less than $2 \mathrm{~mm}$ anteriorly and a second case displayed a maxillary midline shift that was partially corrected with post-operative orthodontics.

Regarding TMJ symptoms, normal joints usually adapt to new occlusal relation. For patients with preexisting joint dysfunction, detailed documentation of muscle and joint dysfunction is mandatory. Orthognathic surgery can potentially improve joint dysfunction through the founding of a balanced, stable, and repeatable occlusion; however, this is challenging to foresee with any degree of confidence $^{23 ; 24}$. Joint symptoms may recover, worsen, or remain similar when compared to the preoperative condition before orthognathic surgery. Fortunately, in the current study none of the treated patient suffers from joint symptom.
Failure of fixation in the mandibular segments are common which may cause significant postoperative complications usually resulting from intra-operative technical inaccuracy. This can be challenging if not corrected early in the postoperative period. It is likely to result in malocclusion, poor healing, and proximal segment rotation where correction would be more difficult. Malocclusion, segment mobility, midline shift and persistent pain and infection are all symptoms of fixation failure. When fixation failure detected early inter-maxillary fixation using wires or heavy elastics could be used. Reoperation and fixation are the treatment of choice in lately detected or severely displaced ones ${ }^{25 ; 26}$.

Fixation failure is rare in upper jaw, and if intermaxillary fixation fails to solve the condition, re operation with more rigid fixation and bone grafting could be mandatory ${ }^{27}$. The present study showed two cases of screw looseness. Conservative treatment was sufficient to correct the condition.

Relapse (either surgical or orthodontic) represent a nightmare for both the surgeon and the orthodontist. Relapse is multifactorial complication however; proper planning; careful bone sectioning and use of rigid fixation could be associated with less surgical relapse ${ }^{28}$. The present case series showed single case of surgical relapse which necessitated re-operation probably due to inadequately fixed bone segments.

Orthognathic surgery offers efficient tool for the correction of facial and occlusal disharmonies. Regardless of surgeon experience, complications are un-separable part of any surgical procedure. In reviewing these complications ${ }^{29 ; 30}$, adequate knowledge are essential to prevent rather than manage these unfortunate events. Patient education and informed consents are essential part for proper handling of these cases. Continued progress in the field of orthognathic surgery, especially with the development of virtual surgical planning, have aided to renovate our treatment planning and bring patients to the best result. 


\section{REFERENCES}

1- Kim SG, Park SS. Incidence of complications and problems related to orthognathic surgery. J Oral Maxillofac Surg 2007;65:2438.

2- Steel B, Cope M. Unusual and rare complications of orthognathic surgery: a literature review. J Oral Maxillofac Surg 2012;70:1678

3- Panula K, Finne K, Oikarinen K. Incidence of complications and problems related to orthognathic surgery: a review of 655 patients. J Oral Maxillofac Surg 2001;59:1128

4- Kim S-G, Park S-S. Incidence of complications and problems related to orthognathic surgery. J Oral Maxillofac Surg 2007;65(12):2438-44

5- Teltzrow T, Kramer F-J, Schulze A, Baethge C, Brachvogel P. Perioperative complications following sagittal split osteotomy of the mandible. J Craniomaxillofac Surg 2005;33(5):307-13.

6- Kim JH, Kim SG, Oh JS. Complications related to orthognathic surgery. J Korean Assoc Maxillofac Plast Reconstr Surg. 2010;32:416-421

7- Jędrzejewski M, Smektała T, Sporniak-Tutak K, Olszewski R. Preoperative, intraoperative, and postoperative complications in orthognathic surgery: a systematic review. Clin Oral Investig. 2015;19:969-977.

8- Jung JY, Park JH, Sin SH, Lee HK, Lee SW, Kim WH, et al. Postoperative complications of bilateral sagittal split ramus osteotomy of mandible. Korean J Hosp Dent. 2006;4:67-81.

9- Brons S, Becking AG, Tuinzing DB. Value of informed consent in surgical orthodontics. J Oral Maxillofac Surg. 2009;67:1021-1025

10- Robinson RC, Holm RL. Orthognathic surgery for patients with maxillofacial deformities. Aorn J 2010; 92(1):28-49.

11- Colella G, Cannavale R, Vicidomini A, Lanza A. Neurosensory disturbance of the inferior alveolar nerve after bilateral sagittal split osteotomy: a systematic review. J Oral Maxillofac Surg 2007;65(9):1707-15

12- Bouloux G, Perciaccante V. Massive hemorrhage during oral and maxillofacial surgery: ligation of the external carotid artery or embolization? J Oral Maxillofac Surg 2009;67:1547-51
13- Lanigan DT, Hey JH, West RA. Major vascular complications of orthognathic surgery: Hemorrhage associated with Lefort I osteotomies. J Oral Maxillofac Surg 1990;48:561.

14- Lanigan D. Vascular complications associated with orthognathic surgery. Oral Maxillofac Surg Clin North Am 1997;9(2):231-50.

15- Patterson AL, Bagby SK. Posterior vertical body osteotomy (PVBO): a predictable rescue procedure for proximal segment fracture during sagittal split ramus osteotomy of the mandible. J Oral Maxillofac Surg. 1999;57:475-477.

16- Shin YM, Lee ST, Kwon TG. Surgical correction of septal deviation after Le Fort I osteotomy. Maxillofac Plast Reconstr Surg. 2016;38:21.

17- Monnazzi MS, Mannarino FS, Gabrielli MFR. Extraoral alar base cinch. A modification for the technique. J Oral Maxillofac Surg Med Pathol. 2014;26:142-144.

18- Shin YM, Lee ST, Kwon TG. Surgical correction of septal deviation after Le Fort I osteotomy. Maxillofac Plast Reconstr Surg. 2016;38:21

19- Jakobsone G, Stenvik A, Sandvik L, Espeland L. Threeyear follow-up of bimaxillary surgery to correct skeletal Class III malocclusion: stability and risk factors for relapse. Am J Orthod Dentofacial Orthop. 2011;139:80-89

20- Proffit WR, Phillips C, Turvey TA. Stability after surgicalorthodontic corrective of skeletal Class III malocclusion. 3. Combined maxillary and mandibular procedures. Int $\mathbf{J}$ Adult Orthodon Orthognath Surg. 1991;6:211-225

21- Han JJ, Park MW, Park JB, Park HS, Paek SJ, Sul H, et al. Evaluation of dominant influencing factor for postoperative relapse after BSSRO for mandibular prognathism. Recent Adv Orthod Orthognath Surg. 2014;1:27-36.

22- Yang HJ, Hwang SJ. Evaluation of postoperative stability after BSSRO to correct facial asymmetry depending on the amount of bone contact between the proximal and distal segment. J Craniomaxillofac Surg. 2014;42:e165-e170

23- Aoyama S, Kino K, Kobayashi J, Yoshimasu H, Amagasa T. Clinical evaluation of the temporomandibular joint following orthognathic surgery - multiple logistic regression analysis. J Med Dent Sci 2005;52(June (2)):109-14

24- Ellis E, 3rd, Hinton RJ. Histologic examination of the temporomandibular joint after mandibular advancement with and without rigid fixation: an experimental investigation in adult Macaca mulatta. J Oral Maxillofac Surg. 1991;49:1316-1327. 
25- Ayoub AF, Lalani Z, Moos KF, Wood GA. Complications following orthognathic surgery that required early surgical intervention: fifteen years' experience. Int J Adult Orthodon Orthognath Surg 2001;16(2):138-44

26-Falter B, Schepers S, Vrielinck L, et al. Plate removal following orthognathic surgery. Oral Surg Oral Med Oral Pathol Oral Radiol Endod 2011; 112:737-43.

27- el Deeb M, Wolford L, Bevis R. Complications of orthognathic surgery. Clin Plast Surg 1989;16(4):825-40.
28- Espeland L, Høgevold HE, Stenvik A. A 3-year patientcentred follow-up of 516 consecutively treated orthognathic surgery patients. Eur J Orthod 2008;30(1):24-30.

29-Morris DE, Lo L-J, Margulis A. Pitfalls in orthognathic surgery: avoidance and management of complications. Clin Plast Surg 2007;34(3):e17-29.

30-Uckan S, Buchbinder D, Orhan M, Mutlu N. Management of early relapse after a sagittal split ramus osteotomy by gradual callus distraction: a case report. J Oral Maxillofac Surg. 2000;58:220-223 